\title{
Monitoring the prevalence of the parasitic dinoflagellate Hematodinium sp. in snow crabs Chionoecetes opilio from Conception Bay, Newfoundland
}

\author{
Gottfried P. Pestal ${ }^{1,4}$, David M. Taylor ${ }^{2, *}$, John M. Hoenig ${ }^{3}{ }^{\text {, Jeffrey D. Shields }}{ }^{3}$ \\ Roger Pickavance ${ }^{1}$

\begin{abstract}
${ }^{1}$ Department of Biology, Memorial University of Newfoundland, St. John's, Newfoundland A1C 5S7, Canada
${ }^{2}$ Department of Fisheries and Oceans, St. John's, Newfoundland A1C 5X1, Canada

${ }^{3}$ Virginia Institute of Marine Science, Gloucester Point, Virginia 23062, USA

${ }^{4}$ Present address: School of Resource and Environmental Management, Simon Fraser University, Burnaby, British Columbia V5A 1S6, Canada
\end{abstract}

\begin{abstract}
Bitter crab disease (BCD) of snow crabs Chionoecetes opilio is caused by a parasitic dinoflagellate, Hematodinium sp. In Newfoundland's commercial fishery, infected snow crabs are identified using visual, macroscopic signs of disease for separation prior to processing. We estimated the sensitivity and specificity of gross, macroscopic diagnosis of Hematodinium sp. by comparing these results with microscopic examination of prepared hemolymph smears. The sensitivity of a diagnostic test is the probability that the test will yield a positive result given that the animal has the disease. The specificity is the probability of a negative result given the animal is not diseased. In October 1998, we conducted a design-based survey using cluster sampling in 2 strata. Over 10000 snow crabs from pot and trawl surveys were examined macroscopically for BCD. In addition, over 350 crabs were randomly examined microscopically for disease. The double sampling resulted in an estimated sensitivity of $52.7 \%$ and an estimated specificity of $100 \%$. That is, a positive result from macroscopic examination is definitive, if the observer is well trained, but macroscopic examination will fail to detect infections in crabs with borderline clinical signs of disease. The prevalence estimated from macroscopic observations ( $\hat{p}_{s t}=2.24 \%$ ) was corrected for misclassification by dividing $\hat{p}_{s t}$ by the estimated sensitivity (0.527), giving a corrected estimate of $4.25 \%$. The use of double sampling provides for efficient estimation of prevalence in that large numbers of crabs can be quickly examined for gross signs of infection and the results corrected for misclassification based on a limited number of observations with a better, but time-consuming test. In addition, the prevalence of macroscopically infected male crabs was lower in a trap survey $(0.57 \%)$ compared to a trawl survey $(1.59 \%)$. In the trawl survey, female crabs had a significantly higher prevalence of macroscopically diagnosed infections than males $(6.34 \%)$. The prevalence of BCD has shown an alarming increase since it was first detected in Newfoundland during the early 1990s. Transmission and mortality studies are warranted to better understand the effect of the disease on its commercially important host.
\end{abstract}

KEY WORDS: Sensitivity $\cdot$ Specificity $\cdot$ Cluster sampling $\cdot$ Disease $\cdot$ Diagnosis

\section{INTRODUCTION}

The snow crab Chionoecetes opilio is currently the most commercially important species harvested in Newfoundland and Labrador. Landings for this fishery peaked in 1999 at $69000 \mathrm{mt}$ with a value in excess of 300 million Canadian dollars. Since the collapse of the groundfish fishery in 1992, the snow crab has been the mainstay of the Province's fishing economy. In 1990, bitter crab disease (BCD) was first observed in snow 
crabs off Newfoundland and it has since been reported in increasing numbers of commercial catches (Taylor \& Khan 1995). The causative agent of BCD, Hematodinium sp., is a parasitic dinoflagellate that lives in the hemolymph of infected crabs (Meyers et al. 1987). The parasite previously damaged the tanner crab (C. bairdi) fishery in SE Alaska and is found in snow crabs C. opilio from the Bering Sea (Meyers et al. 1987, 1990, 1996). At present, it is not clear if the same species of Hematodinium occurs in both Alaska and Newfoundland.

Epizootics of Hematodinium spp. have affected several important fisheries. The American blue crab Callinectes sapidus fishery has suffered significant annual mortalities in high-salinity waters of Maryland and Virginia (Messick 1994, Messick \& Shields 2000). The Norway lobster Nephrops norvegicus fishery in Scotland has lost an estimated £2 to 4 million annually to a Hematodinium-like parasite (Field et al. 1992, Field \& Appleton 1995). The French velvet crab Necora puber fishery suffered a catastrophic decline due to $H$. perezi (Wilhelm \& Boulo 1988, Wilhelm \& Miahle 1996), and the edible crab Cancer pagurus fishery was also affected by the same or a similar agent (Latrouite et al. 1988). Given the negative effects of Hematodinium spp. on other fisheries and their industries, $\mathrm{BCD}$ represents a significant threat to Newfoundland's snow crab fishery.

Preliminary data indicate that since 1990, the prevalence of Hematodinium sp. in snow crabs off Newfoundland has increased, but until now there have been no quantitative surveys of prevalence (Taylor \& Khan 1995, D. M. Taylor unpubl. data). Changes in prevalence from one survey to the next can reflect the dynamics of the disease but they can also reflect changes in the composition of the host population due to other factors such as differential fishing pressure, differential migration patterns, or changed sampling procedures. Such changes underscore the need to study factors affecting prevalence in order to better understand the dynamics of the disease.

In 1997, we initiated a study of BCD in snow crabs in Newfoundland. The objectives were: (1) to develop a sampling design and protocol to estimate the prevalence of BCD in snow crabs that accounted for the fact that observations are obtained from clusters of crabs and that made use of the double-sampling theory for increased efficiency; (2) to obtain the first quantitative estimates of prevalence in a pilot study in Conception Bay, Newfoundland; (3) to compare the performance of 2 methods used in detecting Hematodinium sp. infections (macroscopic visual examination versus microscopic evaluation of hemolymph smears). We also report on temporal increases in $\mathrm{BCD}$, differences in prevalence with sampling gear, and differences in prevalence between host sexes.

\section{MATERIALS AND METHODS}

Sampling design and protocol. The prevalence survey took place in Conception Bay, Newfoundland, during the annual stock assessment survey from 28 September to 9 October 1998. For developing the prevalence estimator, the bay was arbitrarily stratified into 2 depth strata (200 to $249 \mathrm{~m}$ and $>250 \mathrm{~m}$ ) with known areas calculated from nautical charts $(58.38$ nautical square miles or $151.2 \mathrm{~km}^{2}$, and 23.39 nautical square miles or $60.58 \mathrm{~km}^{2}$, respectively). A shallower stratum, $<200 \mathrm{~m}$ in depth, was also sampled, but there were only 3 trap and 2 trawl stations below $200 \mathrm{~m}$; those stations were not included in the analyses.

Stations were chosen randomly for each day. Crabs were sampled at each station with either a fleet of traps or a trawl or both. Thus, each station provided a cluster sample. Traps were deployed in 'fleets' of 8 standard Japanese conical traps, 5 of which had $13.1 \mathrm{~cm}$ mesh and 3 of which had $3.1 \mathrm{~cm}$ mesh. Each trap was baited with $3 \mathrm{~kg}$ of previously frozen northern shortfin squid Illex illecebrosus and Atlantic mackerel Scomber scombrus. The standard soak time for traps was $24 \mathrm{~h}$, but because of weather conditions in the autumn actual soak times varied from 16 to $139 \mathrm{~h}$. For trawls, a lined No. 36 shrimp trawl with a 'tickler' chain and SCANMAR sensors was dragged across the bottom for 10 min at a speed of 2.5 knots.

Most of the captured snow crabs were examined but, because of logistical constraints associated with the handling of thousands of individuals, some crabs were only counted. When traps were retrieved, the procedure was to place the contents of each trap into a separate basket. When a basket was filled, the crabs within were examined. The remaining crabs from the trap were sexed, counted and released. Using this procedure, over $80 \%$ of the captured crabs were examined. When trawls were retrieved, the catch was rinsed with seawater, snow crabs were sorted into baskets, and all non-target species were released. In most cases, all of the baskets containing snow crabs were processed as for traps. However, in 2 trawls, too many crabs were collected to be sampled. In these trawls, 5 baskets containing snow crabs were randomly selected and processed as for traps. Snow crabs in baskets that were not selected were counted by sex. Using this procedure, over $81 \%$ of the crabs were examined.

A subsample of hemolymph was taken from every eighth crab processed in the trawl survey, except for certain days on which no hemolymph sampling was done. No bias arises from not sampling on some days because each day's station locations were selected randomly. A previous pilot study indicated that 1 in 8 crabs could be subsampled by 1 person without slowing the standard survey sampling during trawl opera- 
tions. In addition, a hemolymph sample or a smear was obtained from every crab that showed macroscopic signs of infection on those days when the disease survey was in effect. No hemolymph samples were taken from crabs in the trap survey.

Sex, carapace width, shell condition and macroscopic signs of bitter crab disease were noted for all the crabs examined. Shell conditions were determined using criteria described by Taylor et al. (1989). The primary macroscopic sign of infection with Hematodinium sp. was a distinct pink or red discoloration to the carapace that gave the crabs a cooked appearance (Fig. 1). Infected crabs also had an opaque, solid white ventrum, listless or lethargic behavior, and milky, discolored hemolymph (Meyers et al. 1990, Taylor \& Khan 1995).

Laboratory procedures. Hemolymph samples were drawn with a 23 gage needle on a $3 \mathrm{ml}$ tuberculin syringe from the arthrodial membrane at the juncture of
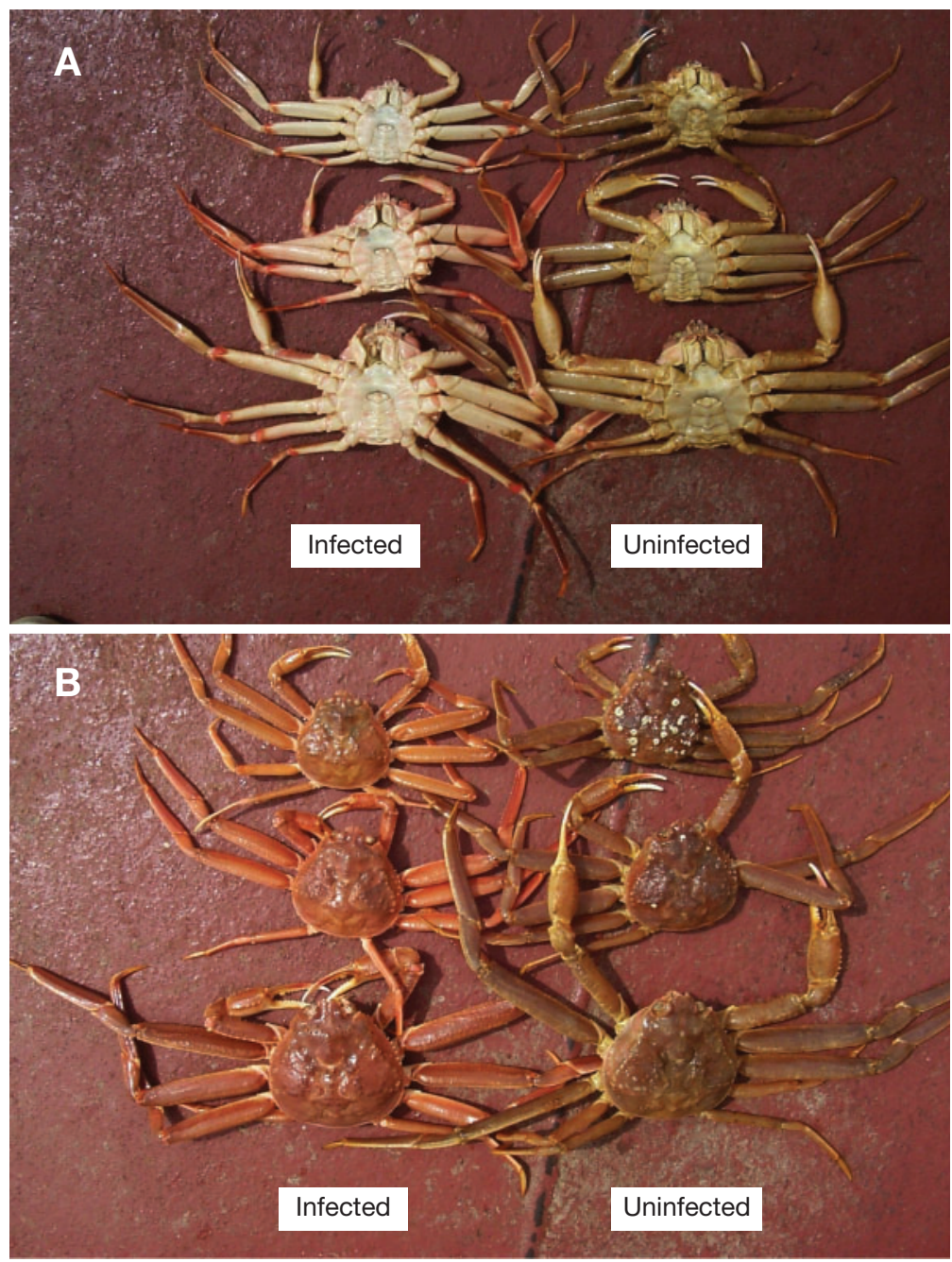

Fig. 1. Chionoecetes opilio. Ventral (A) and dorsal (B) aspect of infected (macroscopically diagnosed) and uninfected snow crabs the basis and the ischium of the cheliped or a walking leg. Hemolymph samples were handled in 1 of 3 ways. Method 1: Hemolymph was placed on an acid-cleaned, poly-l-lysine-coated microslide, fixed immediately in Bouin's solution, and transported in Bouin's solution to the laboratory for further processing. Method 2: Small crabs (<40 mm carapace width) were bled by detaching the dactyl from a walking leg, squeezing out a drop of hemolymph onto a slide, and drying the thick smear for later processing. Method 3: Due to the difficulty of using fixatives in Coplin jars while at sea, we also used a cold fixation method. Briefly, a uniquely coded $3 \mathrm{ml}$ syringe with a 23 gage needle was preloaded with $1 \mathrm{ml}$ ice-cold, $10 \%$ formalin in filtered seawater. Crab hemolymph was drawn into a syringe at a proportion of approximately 1:2 to 1:5 hemolymph to fixative. The fixed hemolymph was gently shaken, stored on ice for transportation, and refrigerated until processed. In the laboratory, aliquots of fixed hemolymph were placed on poly-l-lysine-coated slides, allowed to settle for $45 \mathrm{~s}$, post-fixed in Bouin's solution for $24 \mathrm{~h}$, and transferred to $70 \%$ ethanol for holding. Regardless of the preparation protocol, all of the smears were hydrated, stained with Jenner-Giemsa for 10 to $20 \mathrm{~min}$ (Presnell \& Schreibmann 1997), dehydrated through an acetone series, cleared in a xylene series, and mounted in cytoseal.

Stained smears were examined with a light microscope at $400 \times$ for 5 min each in random order and with coded identification numbers to prevent bias. Smears were classified as 'infected' when at least 1 clearly identifiable Hematodinium sp. cell of any stage was found (Meyers et al. 1987, Taylor \& Khan 1995). Identification was based on cell size and the presence of condensed chromatin in the nucleus (a feature of the dinoflagellates; Chatton \& Poisson 1931).

Estimating prevalence based on macroscopic criteria. Each fleet (set) of traps and each tow of the trawl provided a cluster sample of crabs. The goal was to combine the observations on prevalences in the clusters into a single estimate of the prevalence in the population. Within a depth stratum $i$, the estimated prevalence, $\hat{p}_{i}$, can be computed as:

$$
\hat{p}_{i}=\frac{\sum_{j=1}^{n_{i}} x_{i j}}{\sum_{j=1}^{n_{i}} z_{i j}}
$$


where $n_{i}$ is the number of clusters sampled in Stratum $i, x_{i j}$ is the number of infected animals in the $j$ th cluster from Stratum $i$, and $z_{i j}$ is the number of crabs captured in the $j$ th cluster from Stratum $i$.

The overall estimate of prevalence, $\hat{p}_{s t}$ is a weighted sum of the stratum estimates, $\hat{p}_{i}$. The weights correspond to the relative abundances of crabs in the strata and thus depend on the size of the strata (i.e. $A_{i r}$ area) and the relative density of crabs in the strata. The former are known from nautical charts and the latter are estimated from the catch rates. The weighting factors are computed as:

$$
\omega_{i}=\frac{A_{i} \bar{z}_{i}}{\sum_{h=1}^{I} A_{h} \bar{z}_{h}}
$$

where $I$ is the number of strata and $\bar{z}_{h}$ is the mean catch per tow (or mean catch per set) of crabs in the $h$ th stratum:

$$
\bar{z}_{h}=\sum_{j=1}^{n_{h}} \frac{Z_{h j}}{n_{h}}
$$

The resulting estimator of prevalence is:

$$
\hat{p}_{s t}=\sum_{i=1}^{I} \omega_{i} \hat{p}_{i}
$$

Using the 'delta' or Taylor's series method (Seber 1982), an estimator for the variance of Eq. (1) can be calculated as (Pestal 1999):

$$
\hat{V}\left(\hat{p}_{s t}\right) \approx \sum_{i=1}^{I} \alpha_{i} \hat{V}\left(\bar{x}_{i}\right)+\sum_{i=1}^{I} \beta_{i} \hat{V}\left(\bar{z}_{i}\right)-2 \sum_{i=1}^{I} \gamma_{i} \operatorname{cov}\left(\bar{x}_{i}, \bar{z}_{i}\right)
$$

where

$$
\begin{gathered}
\alpha_{i}=\left(\frac{A_{i}}{V}\right)^{2}, \quad \beta_{i}=\left(\frac{A_{i} u}{V^{2}}\right)^{2}, \quad \gamma_{i}=\frac{A_{i}^{2} u}{V^{3}}, \text { and } \\
\bar{x}_{i}=\frac{\sum_{j=1}^{n_{i}} x_{i j}}{n_{i}}
\end{gathered}
$$

Here $u=\sum_{h=1}^{I} A_{h} \bar{x}_{h} \quad$ and $\quad v=\sum_{h=1}^{I} A_{h} \bar{z}_{h}$

In the special case where $I=1$ stratum, the variance formula simplifies to that for simple cluster sampling (Dawe et al. 1993):

$$
\hat{v}(\hat{p})=\frac{\sum_{j=1}^{n}\left(x_{j}-\hat{p} z_{j}\right)^{2}}{n(n-1) \bar{z}^{2}}
$$

Sensitivity and specificity. Although hemolymph smears do not provide a perfectly reliable test because recently infected individuals may have too few parasite cells to be detected, we treated the smears as the standard against which macroscopic observations could be compared.
The sensitivity and specificity of the macroscopic test were estimated in 2 ways. First, the systematic sample of every eighth crab was examined by both diagnostic methods, and the results were summarized in a crossclassified $2 \times 2$ table (Table 1). From this, the sensitivity, $S_{\mathrm{e}}$ and specificity, $S_{\mathrm{p}}$, of the macroscopic approach could be estimated as:

$S_{\mathrm{e}}=\frac{\text { number infected according to both methods }}{\text { number infected according to smear }}$

and

$S_{\mathrm{p}}=\frac{\text { number not infected according to both methods }}{\text { number not infected according to smear }}$

Second, additional information was available about the sensitivity and specificity of the macroscopic approach because every crab designated positive for the disease according to macroscopic criteria was further tested by examination of the hemolymph. We incorporated this additional information by viewing the macroscopic examination of all crabs as providing a (post-)stratification of the observations into 2 categories ('macroscopically positive' and 'macroscopically negative'). Each of these 2 categories was then subsampled with hemolymph slides prepared for about half of the 'macroscopically positive' crabs and for one-eighth of the 'macroscopically negative' crabs.

With this approach we then let $Q_{0}$ be the number of crabs visually examined that are macroscopically negative and $Q_{1}$ be the number macroscopically positive. Let $q_{0}$ and $q_{1}$ be the number of crabs drawn from the $Q_{0}$ and $Q_{1}$ individuals, respectively, that are examined microscopically. The results of the microscopic examinations are summarized as counts, $R_{i j}$, for $i$ and $j$ taking values 0 and 1 , with $i$ denoting the result of the microscopic test, $j$ denoting the result of the microscopic test, 0 denoting uninfected, and 1 denoting infected. Thus, for example, $R_{01}$ denotes the number of crabs classified as uninfected by the microscopic method and infected by the macroscopic method.

The sensitivity and specificity are then estimated by:

$$
\begin{aligned}
& S_{\mathrm{e}}=\frac{\left(r_{11} / q_{1}\right) Q_{1}}{\left(r_{11} / q_{1}\right) Q_{1}+\left(r_{10} / q_{0}\right) Q_{0}} \\
& S_{\mathrm{p}}=\frac{\left(r_{00} / q_{0}\right) Q_{0}}{\left(r_{00} / q_{0}\right) Q_{0}+\left(r_{01} / q_{1}\right) Q_{1}}
\end{aligned}
$$

These equations make use of Bayes' Rule:

$$
\operatorname{Pr}(J=j \mid I=i)=\frac{\operatorname{Pr}(I=i \mid J=j) \operatorname{Pr}(J=j)}{\sum_{h=0}^{1} \operatorname{Pr}(I=i \mid J=h) \operatorname{Pr}(J=h)}
$$

where $I$ and $J$ are random variables representing the outcome of the microscopic and macroscopic tests, 
respectively, when the tests are applied to a randomly selected individual. In the last equation, the numerator represents the probability of the joint outcome of the 2 tests (joint probability $=$ conditional probability of microscopic result given the macroscopic result $\times$ probability of getting the macroscopic result). The denominator represents the marginal probability of getting Outcome $i$ with the microscopic test.

Correcting estimated prevalence for misclassification. The estimated prevalence based on macroscopic criteria, $\hat{p}_{s t}$, was corrected for misclassification as follows. The estimated prevalence arises as the sum of 2 components: truly infected crabs that test positive by macroscopic criteria, and truly uninfected crabs that test positive (false positives). Let the proportion 'truly infected' be denoted by $\Pi$. Then $\hat{p}_{s t}$ can be expressed as:

$$
\hat{p}_{s t}=S_{\mathrm{e}} \Pi+\left(1-S_{\mathrm{p}}\right)(1-\Pi)
$$

This can be solved for $\Pi$ to obtain a moment estimator, $\hat{\Pi}$, for $\Pi$ :

$$
\hat{\Pi}=\frac{\hat{P}_{s t}+S_{\mathrm{p}}-1}{S_{\mathrm{e}}+S_{\mathrm{p}}-1}
$$

In the special case where specificity equals 1.0, the estimator reduces to

$$
\hat{\Pi}=\frac{\hat{P}_{s t}}{S_{\mathrm{e}}}
$$

\section{RESULTS}

\section{Prevalence as determined by macroscopic diagnosis}

Overall, 10165 snow crabs Chionoecetes opilio were examined macroscopically: 5458 from the trap survey and 4707 from the trawl survey. Of these, 31 crabs in the trap and 108 crabs in the trawl surveys were visually positive for infection for an overall apparent, or macroscopically diagnosed, prevalence of $1.37 \%$. However, the apparent prevalence of infection in males was $0.57 \%$ in the trap survey (Table 2 ) and $1.59 \%$ in the trawl survey (Table 3), indicating significant differences between survey methods (i.e. trap bias for adult males) in catching and predicting the prevalence of macroscopically diagnosed infections (chi-square = 23.79, $\mathrm{df}=1, \mathrm{p}<0.001$; no overlap, with $\pm 2 \mathrm{SE} ; \mathrm{p}<0.05)$.

Host sex was a distinct factor influencing the prevalence of infections of Hematodinium sp. In the trawl survey, male snow crabs had a significantly lower prevalence than females (Tables $3 \& 4: 1.59$ and $1.68 \%$ vs 6.34 and $7.23 \%$, respectively, no overlap, with $\pm 2 \mathrm{SE}_{\mathrm{i}} \mathrm{p}<0.05$ ). Whether these differences were a result of fishing bias toward male crabs, a predilection
Table 1. Chionoecetes opilio. Summary of prevalence data

\begin{tabular}{|c|c|c|c|c|}
\hline Source & $\begin{array}{l}\text { Micros } \\
\text { positive }\end{array}$ & $\begin{array}{l}\text { opically } \\
\text { negative }\end{array}$ & Total & $\%$ infected \\
\hline \multicolumn{5}{|c|}{ Macroscopically } \\
\hline positive & 9 & 0 & 9 & 100.000 \\
\hline negative & 7 & 326 & 333 & 2.102 \\
\hline Total & 16 & 326 & $355^{*}$ & 4.507 \\
\hline
\end{tabular}
from the systematic survey of the trawl data showing sensitivity and specificity of macroscopic test

Table 2. Chionoecetes opilio. Prevalence of macroscopically diagnosed Hematodinium sp. infections in snow crabs (by station) for 19 fleets of 8 traps fished during the 1998 Conception Bay assessment cruise. $N_{\mathrm{p}}$ : number parasitized; $N_{\mathrm{T}}$ : total

\begin{tabular}{|c|c|c|c|c|}
\hline Stn & Depth (m) & $N_{\mathrm{P}}$ & $N_{\mathrm{T}}$ & Prevalence \\
\hline 1 & $196^{\mathrm{a}}$ & 2 & $352^{\mathrm{b}}$ & 0.0057 \\
\hline 2 & 209 & 2 & 342 & 0.0059 \\
\hline 3 & $190^{\mathrm{a}}$ & 0 & $392^{\mathrm{b}}$ & 0.0000 \\
\hline 4 & 222 & 1 & 392 & 0.0026 \\
\hline 5 & 228 & 4 & 356 & 0.0112 \\
\hline 6 & 262 & 2 & 291 & 0.0069 \\
\hline 7 & 272 & 3 & 359 & 0.0084 \\
\hline 8 & $175^{\mathrm{a}}$ & 0 & $246^{\mathrm{b}}$ & 0.0000 \\
\hline 9 & 226 & 2 & 298 & 0.0067 \\
\hline 10 & 214 & 1 & 199 & 0.0050 \\
\hline 11 & 277 & 1 & 266 & 0.0038 \\
\hline 12 & 258 & 7 & 268 & 0.0261 \\
\hline 13 & 267 & 0 & $193^{\mathrm{b}}$ & 0.0000 \\
\hline 14 & 257 & 2 & 166 & 0.0121 \\
\hline 15 & 263 & 0 & 339 & 0.0000 \\
\hline 16 & 257 & 0 & 336 & 0.0000 \\
\hline 17 & 223 & 0 & 260 & 0.0000 \\
\hline 18 & 246 & 3 & $199^{b}$ & 0.0151 \\
\hline 19 & 244 & 1 & $204^{\mathrm{b}}$ & 0.0049 \\
\hline \multicolumn{2}{|c|}{$\begin{array}{l}\text { Total } \\
\text { Variance = }\end{array}$} & 31 & 5458 & $\begin{array}{c}0.0057 \\
2.095 \times 10^{-6}\end{array}$ \\
\hline \multicolumn{2}{|c|}{$\begin{array}{l}>199 \mathrm{~m}^{\mathrm{a}} \\
\text { Variance }=\end{array}$} & 29 & 4468 & $\begin{array}{c}0.0065 \\
2.775 \times 10^{-6}\end{array}$ \\
\hline \multicolumn{5}{|c|}{$\begin{array}{l}\text { b Includes in descending order in colums: } 1,10,1,1,1 \text { and } \\
5 \text { female crabs; } 1 \text { infected female crab was included for } \\
\text { Stn } 18\end{array}$} \\
\hline
\end{tabular}
number sampled per station. Variance estimated as in Dawe et al. (1993). Traps were biased toward legal-sized males

of the parasite for female or juvenile crabs, or an increased susceptibility of females or juveniles to the disease was not determined.

The stratification method provided an increase in precision only when there were large differences in prevalence between strata. The estimated prevalence 
Table 3. Chionoecetes opilio. Prevalence of macroscopically diagnosed Hematodinium sp. infections in snow crabs (by station) for 24 trawls during the 1998 Conception Bay assessment cruise. $N_{\mathrm{p}}$ : number parasitized; $N_{\mathrm{T}}$ : total number sampled per station. Variance estimated as in Dawe et al. (1993)

\begin{tabular}{|c|c|c|c|c|c|}
\hline \multirow{2}{*}{$\begin{array}{c}\text { Stn } \\
1\end{array}$} & \multirow{2}{*}{$\begin{array}{c}\begin{array}{c}\text { Depth } \\
\text { (m) }\end{array} \\
201\end{array}$} & \multicolumn{2}{|c|}{\begin{tabular}{c}
\multicolumn{2}{c}{ Males } \\
$N_{\mathrm{P}} / N_{\mathrm{T}}$ prevalence
\end{tabular}} & \multicolumn{2}{|c|}{$\begin{array}{c}\text { Females } \\
N_{\mathrm{P}} / N_{\mathrm{T}} \text { prevalence }\end{array}$} \\
\hline & & $0 / 266$ & 0.0000 & $3 / 23$ & 0.1304 \\
\hline 2 & 229 & $4 / 452$ & 0.0089 & $0 / 16$ & 0.0000 \\
\hline 3 & 224 & $0 / 60$ & 0.0000 & $0 / 1$ & 0.0000 \\
\hline 4 & 245 & $2 / 325$ & 0.0062 & $1 / 62$ & 0.0161 \\
\hline 5 & 226 & $1 / 229$ & 0.0044 & $0 / 7$ & 0.0000 \\
\hline 6 & 260 & $4 / 195$ & 0.0205 & $3 / 41$ & 0.0732 \\
\hline 7 & 270 & $2 / 346$ & 0.0058 & $1 / 1$ & 1.0000 \\
\hline 8 & $152^{\mathrm{a}}$ & $1 / 84$ & 0.0119 & $2 / 16$ & 0.1250 \\
\hline 9 & 224 & $2 / 203$ & 0.0099 & $2 / 27$ & 0.0741 \\
\hline 10 & 224 & $2 / 161$ & 0.0124 & $0 / 4$ & 0.0000 \\
\hline 11 & 282 & $3 / 113$ & 0.0266 & $1 / 3$ & 0.3333 \\
\hline 12 & 231 & $0 / 131$ & 0.0000 & $0 / 12$ & 0.0000 \\
\hline 13 & 279 & $5 / 171$ & 0.0292 & $2 / 21$ & 0.0952 \\
\hline 20 & $91^{\mathrm{a}}$ & $0 / 160$ & 0.0000 & $0 / 89$ & 0.0000 \\
\hline 21 & 243 & 1/206 & 0.0049 & $0 / 6$ & 0.0000 \\
\hline 22 & 250 & $11 / 228$ & 0.0483 & 9/95 & 0.0947 \\
\hline 23 & 235 & 0/30 & 0.0000 & $0 / 1$ & 0.0000 \\
\hline 24 & 252 & $1 / 54$ & 0.0185 & $2 / 14$ & 0.1429 \\
\hline 25 & 247 & $7 / 135$ & 0.0519 & $3 / 58$ & 0.0517 \\
\hline 26 & 235 & $3 / 95$ & 0.0316 & $4 / 47$ & 0.0851 \\
\hline 27 & 248 & $6 / 154$ & 0.0390 & $2 / 33$ & 0.0606 \\
\hline 28 & 213 & $5 / 90$ & 0.0556 & $2 / 40$ & 0.0500 \\
\hline 29 & 204 & $6 / 199$ & 0.0302 & $5 / 46$ & 0.1087 \\
\hline 30 & 206 & $0 / 67$ & 0.0000 & $0 / 0$ & 0.0000 \\
\hline \multirow{2}{*}{\multicolumn{2}{|c|}{$\begin{array}{l}\text { Total } \\
\text { Variance }=\end{array}$}} & $66 / 4154$ & 0.0159 & $42 / 663$ & 0.0634 \\
\hline & & & $1.200 \times 10^{-5}$ & & $1.525 \times 10^{-4}$ \\
\hline \multirow{2}{*}{\multicolumn{2}{|c|}{$\begin{array}{l}>199 \mathrm{~m}^{\mathrm{a}} \\
\text { Variance }=\end{array}$}} & $65 / 3910$ & 0.0166 & $40 / 558$ & 0.0717 \\
\hline & & & $1.339 \times 10^{-5}$ & & $9.864 \times 10^{-5}$ \\
\hline
\end{tabular}

and standard error computed from the stratified data for the male snow crabs were very similar to results obtained when prevalence was estimated ignoring the stratification. This was true for data from both the trap and trawl samples. This was because differences in prevalence between the 2 strata were negligible. However, the stratification method indicated that female snow crabs from the shallow stratum had a significantly lower prevalence than those from the deeper stratum $(5.74$ vs $10.29 \%$, respectively, no overlap, $\pm 2 \mathrm{SE}, \mathrm{p}<0.05$; Table 4). No such difference was observed for the male crabs in the trawl survey.

\section{Sensitivity and specificity}

Shipboard hemolymph samples fixed in syringes containing cold formalin and processed as wet smears
Table 4. Chionoecetes opilio. Estimated prevalences and variances of macroscopically diagnosed Hematodinium sp. infections in snow crabs derived from the stratification of depth (weighted prevalences and delta series method for variances). Shallow: crabs from 200 to $249 \mathrm{~m}$; deep: crabs from $>250 \mathrm{~m}$

\begin{tabular}{|lccc|}
\hline \multirow{2}{*}{ Estimator } & \multirow{2}{*}{ Traps } & \multicolumn{2}{c|}{ Trawls } \\
& males & males & females \\
\hline$\hat{p}_{i}$ shallow & 0.0062 & 0.0139 & 0.0574 \\
$\hat{p}_{i}$ deep & 0.0068 & 0.0235 & 0.1029 \\
$\hat{p}_{\text {st }}$ & 0.0064 & 0.0168 & 0.0723 \\
Var $\hat{p}_{\text {st }}$ & $2.052 \times 10^{-6}$ & $1.348 \times 10^{-5}$ & $7.623 \times 10^{-5}$ \\
\hline
\end{tabular}

on poly-l-lysine-coated slides (Method 3: see subsection 'Laboratory procedures') and those fixed immediately in Bouin's solution in Coplin jars (Method 1) gave excellent results in determining the presence and severity of infections. Both methods were superior to air-dried thick smears (Method 2) for diagnosis because the latter introduced significant artifacts in hemocyte and parasite morphology.

The systematic sample of every eighth crab in the trawl survey resulted in a sample of 355 crabs (Table 1). Of these, 9 crabs showed macroscopic signs of the disease while 346 did not (apparent prevalence $=2.53 \%$ ). Hemolymph smears were examined from all 9 macroscopically positive and 333 of the macroscopically negative crabs (samples from 13 macroscopically negative crabs were lost). All of the 9 apparently infected crabs tested positive for the presence of Hematodinium sp. when hemolymph smears were examined. Of the $333 \mathrm{ap}-$ parently uninfected crabs, microscopic examination revealed Hematodinium sp. cells in $7(2.10 \%)$ of the smears. Because 13 slides from the apparently uninfected category were lost, it was not valid to apply the simple formulae for sensitivity and specificity (Eqs. 2 \&3). However, application of Eqs. (4) \& (5) gave the following estimates: sensitivity $=0.527$; specificity $=1.000$.

\section{Correcting estimated prevalence}

We derived a general estimator applicable to estimates of disease prevalence from an area that was arbitrarily stratified by depth and used it to estimate prevalences and variances of BCD in Conception Bay (Table 4). Because there were too few stations represented in the shallowest stratum $(<200 \mathrm{~m})$, we dropped it from the estimates (see also Tables $2 \& 3$ ). For both the trawl and trap surveys, the standard estimates of prevalence (total number parasitized/total number sampled) were close to the weighted estimates.

In the trawl survey, the prevalence of cryptic infections or macroscopically negative but microscopically 
positive infections was 7 out of 333 crabs, or $2.10 \%$ (Table 1). Thus, the estimated prevalences obtained from macroscopically diagnosed infections (Table 4: $\hat{p}_{s t}=0.64,1.68$, and $7.23 \%$, males in the trap survey, males in the trawl survey and females in the trawl survey, respectively) can be corrected for misclassification by dividing estimated prevalence $\left(\hat{p}_{s t}\right)$ by the estimated sensitivity $(0.527$; Eq. 4$)$, giving corrected estimates of prevalence of $1.21 \%$ for males in the trap survey, $3.17 \%$ for males in the trawl survey, and $13.32 \%$ for females in the trawl survey that includes both macroscopically and microscopically infected crabs.

\section{DISCUSSION}

\section{Prevalence}

In Conception Bay, Newfoundland, the prevalence of Hematodinium sp. infections in Chionoecetes opilio has increased markedly over time. In the 1992 to 1993 fishery assessment, the prevalence determined macroscopically for bitter crab disease (BCD) in male crabs caught in traps was $0.037 \%$ ( $\mathrm{n}=5$ of 12012 crabs), with a single sample of 135 crabs caught in April having a relatively high prevalence of $3.7 \%$ (Taylor \& Khan 1995). In the 1998 fishery assessment (present study), the prevalence of macroscopically diagnosed BCD in trapped male crabs was 0.57 vs $1.60 \%$ in the trawled crabs ( $\mathrm{n}=31$ of 5439 and 108 of 4154, respectively), with very low estimated variances. There was an additional $2.10 \%$ prevalence of crabs with asymptomatic infections in the trawl survey. If females are included, the overall prevalence in the trawl survey was $4.25 \%$ including macroscopically and microscopically diagnosed infections. Given the similar sample sizes between survey years, the recent prevalences are 1 to 2 orders of magnitude higher than that previously reported from traps $(0.037 \%$, Taylor \& Khan 1995$)$ and indicate (1) an increase in the prevalence of BCD in the region's commercially important snow crab industry as seen in males from traps, (2) an underestimate of prevalence in crabs taken from traps, and (3) a higher prevalence in females than in males.

The higher prevalence of disease in crabs from trawl samples indicates a distinct bias in collection methods. Similar biases were noted for velvet crabs Necora puber infected with Hematodinium sp. off Brittany, France. Trawl samples had significantly higher prevalences than pot (trap) samples primarily due to nonselective catching of healthy and listless, diseased crabs (Wilhelm \& Boulo 1988, Wilhelm \& Miahle 1996). In the present study, the trawl samples probably had higher prevalences because of non-selective sampling of infected and uninfected crabs, but the trawls also had a lower minimum size of retention than the traps and prevalence tended to be higher in smaller crabs than in larger crabs (D. M. Taylor unpubl. data). Further, the significant difference in prevalence between males and females in the trawl survey suggests that the disease is more prevalent in the smaller female crabs, which are not removed by the fishery and which are not typically monitored by management agencies. Interestingly, Meyers et al. (1990) reported no differences in prevalence between sexes and no differences in prevalence with depth for infections in the tanner crab Chionoecetes bairdi fishery. This may have resulted from these authors' use of commercial traps rather than trawls to survey the disease.

Macroscopic signs of BCD become more pronounced as epizootics progress from June through September (Meyers et al. 1987, 1990). In snow crabs from Newfoundland, anecdotal observations based on macroscopically diagnosed BCD infections indicate that the disease appears to be more prevalent at the end of the commercial fishing season (October) than at the beginning of the season (May to June) (D. M. Taylor unpubl. data). In the more heavily infected tanner crab fishery of SE Alaska, the prevalence and intensity of BCD infections increased through spring into late summer (August), then declined through autumn, falling to zero in late winter as previously infected crabs died (Meyers et al. 1990, Eaton et al. 1991, Love et al. 1993). This implies that prevalence estimates made from visual, macroscopic examinations at different times of the year are not comparable and comparisons should be based on standardized surveys. Infections with Hematodinium spp. in other species of crabs follow cycles that may be associated with host molting (Meyers et al. 1990, 1996, Eaton et al. 1991), maturation (Messick 1994) and seasonality (Eaton et al. 1991, Messick \& Shields 2000). Summer peaks in Hematodinium sp. infections occur in tanner crabs Chionoecetes bairdi just after molting, but it is not clear if transmission is occurring at this time (Meyers et al. 1990, Eaton et al. 1991). Summer peaks in H. perezi infections of blue crabs, Callinectes sapidus, occur well after the main molting period. However, the disease is more common in juvenile than adult blue crabs and may be related to frequency of molting in juveniles (Messick 1994, Shields 1994, Messick \& Shields 2000) or intense fishing pressure on and removal of adults. Therefore, we recommend that estimates be based on unbiased collection methods that include females and pre-recruits or that estimates be made separately for each component of the population. In addition, seasonal samples that include periods with peak prevalences should be obtained to more fully assess the distribution of the parasite and its impact on the fishery. 


\section{Diagnostic procedures}

Comparison of diagnostic procedures based on macroscopic criteria and microscopic examination of hemolymph smears revealed that the macroscopic procedure had high specificity (estimate $=1.000$ ). That is, macroscopic signs of infection were specific to the disease. On the other hand, the sensitivity of the macroscopic procedure was 0.527 , suggesting that nearly half the infected individuals could be missed if the macroscopic procedure alone were used. The relatively low sensitivity estimate highlights 2 important phenomena: (1) prevalence based solely on macroscopic diagnosis in October was underestimated by approximately $50 \%$, a finding that has significant ramifications for estimating the impact of the disease on the fishery; (2) crabs exhibiting macroscopic signs of infection are in advanced stages of the disease (Meyers et al. 1987). For effective diagnosis, visual, macroscopic identification is highly repeatable if the observations are made by trained observers; however, overall prevalence will be largely under-reported. A more complete assessment of prevalence and the diagnosis of BCD must rely on microscopic examination of hemolymph (Meyers et al. 1990), histological sections (Field \& Appleton 1995), immunological detection (Field \& Appleton 1996), or molecular techniques (e.g. Hudson \& Adlard 1994, 1996, Gruebl et al. 2002).

The duration of infection and the ability to detect microscopic infections (detectability) have been examined in tanner and blue crabs experimentally infected with Hematodinium spp. (Meyers et al. 1987, Eaton et al. 1991, Shields \& Squyars 2000). Infections were detectable in the hemolymph of experimentally infected tanner crabs after 55, 69, and 97 d post-inoculation (Meyers et al. 1987), but sample sizes were too low for statistical representation. The duration of infection could last as long as 399 to $419 \mathrm{~d}$ before sporulation occurred (Eaton et al. 1991). In the temperate-water blue crab, infections were detectable in 30 to $35 \%$ of experimentally infected hosts after 14 to $18 \mathrm{~d}$, reaching 80 to $85 \%$ after 26 to $32 \mathrm{~d}$, and $100 \%$ after 35 d (Shields \& Squyars 2000). Histological examinations of the heart indicated 80 to $100 \%$ detection after 3 to $5 \mathrm{~d}$ post-inoculation. The timeto-development of the pink carapace, i.e. a high intensity, terminal infection, has not been reported in snow crabs, and discoloration of the carapace rarely occurs in infections in the blue crab (J. D. Shields unpubl. data). Thus, while we do not directly report on the ability to detect microscopic infections from infection challenges, our data indicate that microscopic infections are at least as common as those observed macroscopically, and may fall along the timescale of 50 to $100 \mathrm{~d}$ post-initial infection, which fits 1 possible time course indicated by Meyers et al. (1987) and Eaton et al. (1991).
For purposes of monitoring the prevalence of the disease, it is necessary to consider the costs associated with a prevalence survey. Use of a molecular probe might provide the most reliable results, but funding for the development of such methodology has not been available. However, in general, when 2 diagnostic procedures are available, with 1 being more reliable but more expensive than the other, increased precision for a fixed cost can be obtained by using a combination of the 2 procedures instead of using just 1 technique. Such combinations of procedures make use of the theory of double-sampling (Tenenbein 1970, Hoenig et al. 2002). Essentially, a large number of error-prone observations can be obtained inexpensively using a technique like macroscopic examination, and then the misclassification rates (sensitivity and specificity) can be estimated by making some observations with both techniques. This approach was adopted in the present study. The estimated specificity for the macroscopic determinations was 1.0 which, if confirmed by further testing, greatly simplifies the procedure and affords greater precision because then only the sensitivity need be estimated in any particular survey.

Acknowledgements. The senior author thanks David Schneider and Jean Finney-Crawley, who served on his Honour's thesis committee. We are indebted to Paul O'Keefe and Paul Collins for their invaluable help, and to the skipper and crew of the 'Shamook'. Three anonymous reviewers improved the manuscript. Travel for J.D.S. was supported, in part, by NOAA, Saltonstall-Kennedy Grant NA76FD0148. This is Contribution 2519 from the Virginia Institute of Marine Science.

\section{LITERATURE CITED}

Chatton E, Poisson R (1931) Sur l'existance, dans le sang des crabs, de peridiniens parasites: Hematodinium perezi n.g., n.sp. (Syndinidae). CR Séances Soc Biol 105:553-557

Dawe EG, Hoenig JM, Xu X (1993) Change-in-ratio and index-removal methods for population assessment and their application to snow crab (Chionoecetes opilio). Can J Fish Aquat Sci 50:1467-1476

Eaton WD, Love DC, Botelho C, Meyers TR, Imamura K, Koeneman T (1991) Preliminary results on the seasonality and life cycle of the parasitic dinoflagellate causing bitter crab disease in Alaskan tanner crabs (Chionoecetes bairdi). J Invertebr Pathol 57:426-434

Field RH, Appleton PL (1995) A Hematodinium-like dinoflagellate infection of the Norway lobster Nephrops norvegicus: observations on pathology and progression of infection. Dis Aquat Org 22:115-128

Field RH, Appleton PL (1996) An indirect fluorescent antibody technique for the diagnosis of Hematodinium sp. infection of the Norway lobster Nephrops norvegicus. Dis Aquat Org 24:199-204

Field RH, Chapman CJ, Taylor AC, Neil DM, Vickerman K (1992) Infection of the Norway lobster Nephrops norvegicus by a Hematodinium-like species of dinoflagellate on the west coast of Scotland. Dis Aquat Org 13:1-15 
Gruebl T, Frischer ME, Sheppard M, Neumann M, Maurer AN, Lee RF (2002) Development of an 18s rRNA gene targeted PCR based diagnostic for the blue crab parasite Hematodinium sp. Dis Aquat Org 49:61-70

Hoenig JM, Hanumara RC, Heisey DM (2002) Generalizing double and triple sampling for repeated surveys and partial verification. Biom J 44:603-618

Hudson DA, Adlard RD (1994) PCR techniques applied to Hematodinium spp. and Hematodinium-like dinoflagellates in decapod crustaceans. Dis Aquat Org 20:203-206

Hudson DA, Adlard RD (1996) Nucleotide sequence determination of the partial SSU rDNA gene and ITS1 region of Hematodinium cf. perezi and Hematodinium-like dinoflagellates. Dis Aquat Org 24:55-60

Latrouite D, Morizur Y, Noël P, Chagot D, Wilhelm G (1988) Mortalité du tourteau Cancer pagurus provoquée par le dinoflagelle parasite: Hematodinium sp. Int Counc Explor Sea Comm Meet ICES/K:32

Love DC, Rice SD, Moles DA, Eaton WD (1993) Seasonal prevalence and intensity of bitter crab dinoflagellate infection and host mortality in Alaskan tanner crabs Chionoecetes bairdi from Auke Bay, Alaska, USA. Dis Aquat Org 15:1-7

Messick GA (1994) Hematodinium perezi infections in adult and juvenile blue crabs Callinectes sapidus from coastal bays of Maryland and Virginia, USA. Dis Aquat Org 19: $77-82$

Messick GA, Shields JD (2000) Epizootiology of the parasitic dinoflagellate Hematodinium sp. in the American blue crab Callinectes sapidus. Dis Aquat Org 43:139-152

Meyers TR, Koeneman TM, Botelho C, Short S (1987) Bitter crab disease: a fatal dinoflagellate infection and marketing problem for Alaskan tanner crabs Chionoecetes bairdi. Dis Aquat Org 3:195-216

Meyers TR, Botelho C, Koeneman TM, Short S, Imamura K (1990) Distribution of bitter crab dinoflagellate syndrome in southeast Alaskan tanner crabs Chionoecetes bairdi. Dis Aquat Org 9:37-43

Editorial responsibility: Timothy Flegel,

Bangkok, Thailand
Meyers TR, Morado JF, Sparks AK, Bishop GH, Pearson T, Urban D, Jackson D (1996) Distribution of bitter crab syndrome in tanner crabs (Chionoecetes bairdi, C. opilio) from the Gulf of Alaska and Bering Sea. Dis Aquat Org 26:221-227

Pestal GP (1999) Prevalence of Hematodinium sp. in the snow crab, Chionoecetes opilio, population of Conception Bay, Newfoundland. BSc Honours thesis, Memorial University, St. John's, Newfoundland

Presnell JK, Schreibmann MP (1997) Humason's animal tissue techniqes, 5th edn. Johns Hopkins University Press, Baltimore

Seber GA (1982) The estimation of animal abundance and related parameters. MacMillan, New York

Shields JD (1994) The parasitic dinoflagellates of marine Crustacea. Annu Rev Fish Dis 4:241-271

Shields JD, Squyars CM (2000) Mortality and hematology of blue crabs, Callinectes sapidus, experimentally infected with the parasitic dinoflagellate Hematodinium perezi. Fish Bull NOAA 98:139-152

Taylor DM, Khan RA (1995) Observations on the occurrence of Hematodinium sp. (Dinoflagellata: Syndinidae), the causative agent of bitter crab disease in Newfoundland snow crab (Chionoecetes opilio). J Invertebr Pathol 65: $283-288$

Taylor DM, Marshall GW, O'Keefe PG (1989) Shell hardening in snow crab tagged in soft-shelled condition. N Am J Fish Manag 9:504-508

Tenenbein A (1970) A double sampling scheme for estimating from binomial data with misclassification. J Am Stat Assoc 65:1350-1361

Wilhelm G, Boulo V (1988) Infection de l'étrille Liocarcinus puber (L.) par un dinoflagelle parasite de type Hematodinium sp. Int Counc Explor Sea Comm Meet ICES/K:41:

Wilhelm G, Mialhe E (1996) Dinoflagellate infection associated with the decline of Necora puber crab populations in France. Dis Aquat Org 26:213-219

Submitted: March 18, 2002; Accepted: August 2, 2002

Proofs received from author(s): December 23, 2002 